\title{
Integrated E-Marketing Adoption Model for Small Businesses
}

\author{
Charles Owuor Omoga \\ Department of Management Science, School of Business Economics and Human Resource Development, \\ Alupe University College (A constituent College of Moi University) Busia, Kenya
}

\begin{abstract}
Small sized businesses play an important role in the growth of economies all over the world, yet they appear to be slow in adopting E-marketing technology to market their products and service .The objective of the study was to develop a model for studying e-marketing adoption among small businesses. A cross sectional survey design was employed on a target population. Stratified random sampling method was used to generate the study sample. Structured self administered questionnaire was used to collect primary data while secondary data were collected via relevant publications and reports. Instrument reliability assessment was confirmed using cronchbas alpha. The data was analyzed using descriptive and inferential analysis using WarpPLS v.5 software. The results show that the predictive relevance of the model $\left(\mathrm{Q}^{2}\right)$ was strong at $47.5 \%$.Policy makers may find these results useful for future policy formulations regarding adoption of e-marketing among small businesses.An Integrated Model for E-marketing adoption was realized in the study that could enhance innovations on small business adoption
\end{abstract}

Keywords: Small businesses, Institutional theory, E-marketing adoption model, Hospitality industry

\section{INTRODUCTION}

Small sized businesses play an important role in the growth of economies all over the world [1]. The contributions of small businesses include job creation; provision of varieties of product to customers; stimulation of competition; distribution of wealth and development of human resources [2]. In the United States of America for example, small businesses represent about $99.7 \%$ of all employer businesses and have generated about $64 \%$ of new employments [3].In Kenya, small and medium enterprises represent $98 \%$ of businesses and also contribute $30 \%$ of jobs created [4].Generally small businesses have been defined in terms of the number of their employees [5]. In Kenya, small businesses have between 11-50 employees [6]. A number of Information Systems adoption models have been developed. Some at individual context while others at organization context. The frequently cited models from the Information Systems discipline include the Technology Acceptance Model (TAM) [7]; Unified Theory of Acceptance and Use of Technology (UTAUT) [8] and Theory of Planned Behavior (TPB) [9]. These models however focus on adoption of Information Systems at individual level. At the organization level, the theories commonly cited include the Diffusion on innovation (DOI) [10] the Technology, Organization, and Environment (TOE) framework [11] and DTOE model [12] Existing literature examining e-marketing adoptions models have focused mainly on economic and rational goals of efficiency [13]. Few studies have investigated Information systems adoption especially E-marketing within the lenses of Institutional theory either individually or combined with other theories yet organizational decisions are driven not only by rational goals of efficiency, but also by Institutional environments which include social factors and legitimacy concerns [14] ; [15].Thus the Institution theory has been underused despite its advantages [14]. Of the few studies that used the Institutional theory, none focused on small businesses context. For this reason, based on literature from Neo-Institutional theory, specifically Institutional isomorphism component [15] and Technology Organization and Environment framework (TOE) [11]. This study sought to develop an Integrated E-marketing adoption model that combines both the economic and rational goals of efficiency and Institutional forces that can be used to study Emarketing Adoption among small businesses

\section{LITERATURE REVIEW}

2.1 Neo- Institutional Theory of Organizations: The Neo- institutional theory posits that organizational decisions are driven not only by rational goals of efficiency, but also by institutional environments which include social factors and legitimacy concerns. This theory asserts that organizations due to isomorphic pressures eventually become similar. This indicates that organization within the same industry tend to become similar progressively as they emulate the industry leaders actions and strategies due to competitive and customer pressures. For example firms may decide to adopt E-marketing not because of internally driven decisions but due to external isomorphic pressures of competitors, trading partners, customers, and government ([16]. Institutional Isomorphism ([16] examined key external pressures 
including Mimetic, Coercive and Normative pressures that make organizations conform to the actions and strategies of other organizations in the industry which they belong. According to [16] Mimetic Pressures refers to the bandwagon effect which means that progressively organizations become more similar to other organizations and imitate best practices adopted by other organizations. Coercive pressures refer to pressures from organisations which the other organisations depend on for business and pressures from socio-cultural expectations in the society within which they are dependent [16].The normative pressures present themselves in the form of professional, associations, trade, and business among others [11]. Authors who have used the Institutional theory have mentioned some limitations which include the following: First, [17] asserted that Institutional theory pays little attention to the role of human agency in institutional changes yet humans do create meaning in complex situations within organizations. Secondly, this theory ignores the fact that technical and resource environment plays an important role in the adoption decisions by organizations [18]. Thirdly, this theory not only focuses on organization field but also ignores the role of geographical distance between organizations yet organizations do not operate in isolation [19].In order to mitigate over these limitations, [19] in their Meta analysis suggested that Institutional theory should be combined with other theories to make it more comprehensive.

2.2 Thongs (1999) DTOE model: 12] separated decision-makers characteristics from organization in TOE and gave it boost to bring the model to Decision-maker, Technology-Organization-Environment (DTOE) proposing that the four conceptual adoption predictors assume a more detailed set of factors that assist in predicting the likelihood of IT adoption among Small businesses. The findings from the DTOE model indicated that significant determinants of small businesses adoption of information systems include leader characteristics like innovativeness \& level of IS knowledge, innovation characteristics including relative advantage, compatibility, complexityofInformation System, organizational characteristics including business size and level of employees' IS knowledge. The study further found that the extent of IS adoption is mainly determined by organizational characteristics and not CEO I.T knowledge or innovativeness. Finally, completive pressure did not influence small business adoption of Information system.

2.2.2 Iacovou et al. (1995) model: [20] developed their model by analyzing characteristics of Interorganizational systems (IOSs) that determine innovation adoptions by organizations of EDI adoption. This model was based on three constructs namely perceived benefits, organizational readiness, and external pressure. Perceived benefits are a different factor from the TOE framework, whereas organizational readiness is a combination of the technology and organization context of the TOE framework. Hence, IT resources were from the technology context while financial resources were from organizational context. The external pressure in the [20] model added the trading partners to the external task environmental context of the TOE framework as a critical role of IOSs adoptions.

\section{MATERIALS AND METHODS}

The location of this study was Kisumu County. This location was relevant for this study because it's an emerging Tourist circuit in Kenya and tourism infrastructure, like hotels and lodges are currently being developed. This study also adopted a quantitative approach. Quantitative studies possess the rigor and coherence that is necessary for addressing the issues and problems [21]. This research also adopted Cross sectional Survey Research Design. According to [22] this sort of survey helps to establish whether significant associations among variables exist. Structured self administered survey questionnaire was employed to collect the primary data from the study respondents. The rationale for using questionnaire is that it is cheaper, flexible and allows for replication of the research procedure thus enhancing validity of research findings.

\section{RESULTS}

4.1 Analysis of Survey response: The analysis of survey response was done to determine the number of respondents who did or didn't respond to the survey. Out of a total of 115 respondents, 106 (92.17\%) responded to the questionnaire while non respondents were nine in number. To avoid bias [23] recommends response rate of $70 \%$ and above for self administered questionnaires.

4.3 Normality testing

Source: Research data (2018)

Table 1: Skewness and kurtosis coefficients

\begin{tabular}{lcc}
\hline Latent variables & Skewness & Kurtosis \\
\hline Managers' IT knowledge & -0.016 & 0.645 \\
Cyber Security concerns & 0.245 & -0.741 \\
Cost of e-marketing & -0.135 & -0.521 \\
Coercive forces & -1.216 & 0.993 \\
Normative forces & -0.399 & -1.314 \\
Mimetic forces & 0.076 & -0.715 \\
Top management support & -0.678 & 0.374 \\
Adoption of E-marketing & -1.602 & 2.584 \\
\hline
\end{tabular}


Vol. 8, Issue 5, May 2019

Univariate normality tests were run for all independent and dependent variables and skewness and kurtosis examined. The common rule-of-thumb for normality is skewness to be within the range of -3 and +3 and Kurtosis to be within the range of negative or positive eight(8) [24].From the analysis, the skewness coefficients for most of the latent variabls were all within the acceptable range of -3 and +3 . According to [22], data in psychometric studies are often not normally distributed. For kurtosis, the coefficients for the latent variables were within the acceptable range. In PLSSEM, the normality of data distribution is never assumed [23] .Table 1 summarizes these findings.

4.4 Assessment of Multicollinearity: A variance inflation factor (VIF) is a measure of the degree of Multicollinearity among the latent variables that are hypothesized to affect another latent variable (predictors). Conservatively, VIF should be lower than 5 although a more relaxed criterion is that they should be lower than 10 [25].All VIF values of the variables were below VIF of ten (10) thus suggesting that there were no latent variables that measured the same thing and hence all latent variables were retained in the model. Table 2 shows the results of full collinearity VIF tests.

Table 2: Multicollinearity assessment results

\begin{tabular}{lc}
\hline Latent variables & Variance Inflation factor (VIF) \\
\hline Managers IT knowledge & 1.194 \\
Security concerns & 1.394 \\
Cost of e-marketing & 1.341 \\
Coercive pressures & 1.028 \\
Normative pressures & 1.677 \\
Mimetic pressures & 1.350 \\
Top management support & 1.511 \\
Adoption of E-marketing & 1.390 \\
\hline
\end{tabular}

Source: Research data $(2018)$

4.5 Outer model estimation (Measurement model): The statistical reliability assessment for the latent variable indicators was done by analyzing the 'outer model' (measurement model) which consisted of the latent variable indicators and the paths connecting them to their respective reflective latent variables. Outer loadings represent the relative contribution of the indicator to the definition of its corresponding latent variable [24]. The loadings should be significant at loadings above .70 [26]. These results show that the indicators of the latent variables used in this model were reliable.

Table 3: Combined Loadings and cross loadings per indicator

\begin{tabular}{ccccccccc}
\hline & Mim & Coer & Norm & Cost & ITkn & Sec & Adopt & MnSupt \\
\hline Mim-1 & $\mathbf{0 . 7 3 3}$ & -0.059 & 0.058 & -0.143 & -0.203 & -0.450 & 0.259 & -0.725 \\
Mim_2 & $\mathbf{0 . 7 5 5}$ & 0.218 & 0.668 & 0.108 & 0.072 & -0.247 & 0.114 & 0.304 \\
Mim_3 & $\mathbf{0 . 9 6 1}$ & 0.074 & 0.302 & -0.000 & -0.034 & -0.249 & 0.131 & -0.103 \\
Coer_1 & -0.138 & $\mathbf{0 . 7 7 1}$ & -0.047 & -0.393 & -0.186 & -0.197 & 0.050 & -0.322 \\
Coer_2 & 0.051 & $\mathbf{0 . 8 7 3}$ & 0.175 & 0.181 & 0.116 & 0.133 & -0.006 & 0.228 \\
Coer_3 & -0.268 & $\mathbf{0 . 7 3 5}$ & 0.644 & -0.597 & -0.142 & -0.103 & 0.157 & -0.123 \\
Norm_1 & -0.053 & -0.003 & $\mathbf{0 . 7 0 5}$ & 0.154 & 0.187 & 0.150 & -0.185 & 0.454 \\
Norm-2 & 0.153 & -0.205 & $\mathbf{0 . 8 6 4}$ & 0.028 & 0.088 & 0.239 & -0.209 & -0.355 \\
Norm-3 & -0.099 & 0.225 & $\mathbf{0 . 7 0 0}$ & -0.222 & -0.328 & -0.445 & 0.456 & -0.186 \\
Cost-1 & 0.041 & 0.255 & 0.304 & $\mathbf{0 . 7 0 6}$ & -0.265 & -0.752 & -0.029 & -0.452 \\
Cost-2 & -0.378 & 0.138 & 0.186 & $\mathbf{0 . 8 5 2}$ & 0.065 & 0.002 & 0.046 & 0.119 \\
Cost-3 & -0.339 & 0.262 & 0.333 & $\mathbf{0 . 8 9 7}$ & -0.074 & -0.384 & 0.029 & -0.119 \\
ITK_1 & -0.057 & -0.168 & -0.115 & 0.029 & $\mathbf{0 . 9 1 0}$ & 0.295 & 0.129 & -0.104 \\
ITK_2 & 0.466 & 0.353 & 0.445 & -0.190 & $\mathbf{0 . 7 8 2}$ & -0.321 & 0.113 & -0.130 \\
ITK_3 & 0.095 & -0.039 & 0.037 & -0.034 & $\mathbf{0 . 8 9 7}$ & 0.162 & 0.150 & -0.134 \\
sec-1 & 0.080 & -0.117 & 0.318 & 0.161 & 0.022 & $\mathbf{0 . 9 2 6}$ & -0.048 & -0.108 \\
Sec-2 & 0.160 & 0.568 & -0.397 & 0.015 & -0.181 & $\mathbf{0 . 7 1 0}$ & -0.051 & 0.469 \\
Sec-3 & -0.139 & -0.038 & -0.241 & -0.187 & 0.030 & $\mathbf{0 . 7 2 8}$ & 0.070 & -0.018 \\
Adopt1 & 0.019 & -0.172 & -0.487 & 0.361 & 0.114 & 0.190 & $\mathbf{0 . 8 9 8}$ & -0.026 \\
Adopt2 & 0.158 & 0.474 & 0.280 & -0.372 & -0.206 & -0.386 & $\mathbf{0 . 8 5 1}$ & -0.039 \\
Adopt3 & -0.108 & -0.093 & 0.331 & -0.153 & 0.002 & 0.026 & $\mathbf{0 . 7 8 6}$ & 0.048 \\
MnSupt1 & 0.215 & -0.247 & 0.082 & 0.232 & -0.019 & 0.036 & -0.026 & $\mathbf{0 . 8 5 9}$ \\
MnSupt2 & 0.040 & -0.360 & 0.377 & -0.039 & -0.037 & -0.534 & 0.514 & $\mathbf{0 . 7 3 2}$ \\
MnSupt3 & 0.208 & -0.158 & -0.014 & 0.246 & -0.010 & 0.174 & -0.159 & $\mathbf{0 . 7 6 6}$ \\
\hline
\end{tabular}

Research data (2018)

Note: Loadings are unrotated and cross-loadings are oblique-rotated, both after separate Kaiser Normalizations. 
Vol. 8, Issue 5, May 2019

4.6 The structural model estimation: This section presents the findings from the analysis of direct relationships between the independent and the dependent latent variables in the model. The path analysis involved using an algorithm in which factor scores were estimated by averaging all the indicators associated with the latent variables. Pvalues were calculated through the process of Resampling. In WarpPLS this was done by using Stable-3 Resampling. Table 4 shows the results of the path analysis.

Table 4: Path analysis results for direct effects (Independent variables to e-marketing)

\begin{tabular}{lllll}
\hline Latent variables & (beta-estimates) & P-values & S.E & $\begin{array}{l}\text { Significance of path } \\
\text { coefficient P<0.05 }\end{array}$ \\
\hline Managers' I.T knowledge & 0.269 & $<0.001$ & 0.090 & Significant \\
Security concerns & -0.158 & 0.047 & 0.095 & Significant \\
Perceived Cost & -0.260 & 0.002 & 0.092 & Significant \\
Coercive pressure & 0.106 & 0.133 & 0.093 & Insignificant \\
Normative pressure & 0.354 & $<0.001$ & 0.087 & Significant \\
Mimetic pressure & 0.176 & 0.019 & 0.092 & Significant \\
Top Management support & 0.277 & 0.001 & 0.090 & Significant \\
E-marketing Adoption intention & & & & \\
\hline
\end{tabular}

Research data (2018)

From table 4, it is observed that the manager's I.T Knowledge emerged is a significant predictor of intention to adopt E-Marketing $(\beta=0.269, \mathrm{p}<0.001)$. Under technological characteristics there were two latent variable namely security concerns and perceived costs of adopting E-marketing. The results indicate that there is a negative relationship between security concerns and adoption of E-Marketing $(\beta=-0.158, p=0.047)$. The results also indicate that there is a negative relationship between Perceived costs and adoption of E-Marketing $(\beta=-0.260, p=0.002)$.This study further examined relationship between Coercive, Normative and Mimetic pressures. The results for Coercive pressures indicate an insignificant relationship with adoption of E-Marketing $(\beta=0.106, p=0.133)$; For Normative pressures, the results indicate a positive relationship with adoption of E-Marketing $(\beta=0.354, p<0.001)$ while results for Mimetic pressures indicate a positive relationship with adoption of E-Marketing $(\beta=0.176, p=0.019)$. Top management support revealed a positive relationship with adoption of E-marketing $(\beta=0.277, \mathrm{p}<0.001)$. The path analysis between the independent variables and Top management support reveals that manager's I.T Knowledge is positively related to Top management $\operatorname{support}(\beta=0.193, p=0.019)$. The results also indicate that there is a negative relationship between security concerns and Top management support $(\beta=-0.163, \mathrm{p}=0.041)$. The results for Perceived costs and Top management support show an insignificant relationship $(\beta=-0.076, p=0.213)$. There was also an insignificant relationship between Coercive pressure and Top management support $(\beta=-0.104, p=0.138)$; For Normative pressure, the results indicate a positive relationship with Top management support $(\beta=0.300, p<0.001)$ while results for Mimetic pressures indicate a positive relationship with Top management support $(\beta=0.176, p=0.030)$. A path coefficient is regarded as significant if its confidence interval does not include the value of zero or if the p-value is below the pre-defined $\alpha$-level [27]

\subsection{Determining the effects of the mediating variable (management support)}

In analyzing relationships with mediating effects a path diagram is recommended when using analytical or descriptive method and the framework commonly adapted by researcher is one by [28] . To this end this study adopted the Baron and Kenny mediation model [28] This model prescribes the following four steps in determining the mediation effect.

1. Determine the relationship between independent variables and dependent variable using regression equation and call it path -c

2. Determine the relationships between independent variables and mediating variable and calling it path -a

3. Determining the relationship between the mediating variable and the dependent variable while controlling for independent variables to establish path $-\mathrm{b}$

4. Establish total mediation if the effect of independent variables on dependent variables is zero while controlling for mediating variable

In this study, step one produced the results from the respondents which investigated the direct relationships between independent variables and dependent variables([28] .Table 5.4 captures these findings. 
Vol. 8, Issue 5, May 2019

Table 5: Direct effects (Path -c; model 1)

\begin{tabular}{llllll}
\hline Latent variables & $(\boldsymbol{\beta}$-estimates $)$ & P-values & S.E & $\begin{array}{l}\text { Significance of } \\
\text { coefficient } \mathrm{P}<0.05\end{array}$ & path \\
\hline Managers I.T knowledge & & & & Significant \\
Security concerns & 0.305 & $<0.001$ & 0.090 & Significant \\
Perceived Cost & -0.084 & 0.018 & 0.095 & Significant \\
Coercive pressure & -0.217 & 0.010 & 0.092 & Insignificant \\
Normative Pressure & 0.054 & 0.288 & 0.093 & Significant \\
Mimetic Pressure & 0.404 & $<0.001$ & 0.087 & Significant \\
E-marketing Adoption & 0.188 & 0.022 & 0.092 & \\
\hline
\end{tabular}

Research data (2018)

From the table 5 it is observed that I.T Knowledge emerged is a significant predictor of adopting E-marketing $(\beta=$ $0.305, \mathrm{p}=<0.001)$. The study also examined the relationship between security concerns and E-Marketing adoption. The results indicate that there is a negative relationship between security concerns and E-Marketing adoption $(\beta=-0.084$, $\mathrm{p}=0.018)$. The results indicate that there is a negative relationship between Perceived costs and E-Marketing adoption $(\beta=-0.217, \mathrm{p}=0.010)$.This study further examined relationship between Institutional pressures and E-Marketing adoption. Under Institutional pressures there were three latent variables namely: Coercive, Mimetic and Normative pressures, the results for Mimetic pressures indicate a positive relationship with e-marketing adoption $(\beta=0.188$, $\mathrm{p}=0.022)$.For Normative pressures, the results indicate a positive relationship with E-marketing adoption $(\beta=0.404$, $\mathrm{p}>0.001)$. The results for Coercive pressures indicate an insignificant relationship with e-marketing adoption $(\beta=$ $0.054, \mathrm{p}=0.288)$.

Step two: Determining the relationship between independent variables and the mediating variable to establish path- a

Step two produced the results from the respondents which investigated the relationships between independent variables and mediating variable. In this step, Owner-managers I.T Knowledge had a positive relationship with Top management support. $(\beta=0.193, p=0.019)$. The study also examined the relationship between security concerns and Top management support. The results indicate that there is a negative relationship between security concerns and Top management support $(\beta=-0.163, \mathrm{p}=0.041)$. The results further indicate that there is an insignificant relationship between Perceived costs and Top management support. $(\beta=-0.076, p=0.213)$. This study also examined relationship between Institutional forces and Top management support. Under Institutional forces there were three latent variables namely: coercive forces, Mimetic pressures and Normative pressures, the results for Mimetic pressures indicate a positive relationship with Top management support. $(\beta=0.176, p=0.030)$. For Normative the results indicate a positive relationship with Top management support. $(\beta=0.300, p<0.001)$. The results for Coercive pressures further indicate an insignificant relationship with Top management support. $(\beta=-0.104, \mathrm{p}=0.138)$. The findings from step two indicate that all the independent variables have significant relationships with the mediating variable (Top management support.) apart from Coercive pressures and perceived cost which had insignificant relationship with Top management support.Accoding to ([28] if an independent variable fails to have a significant relationship with the mediating variabls, the further mediating analysis is stopped for that variable. Table 6 shows these results

Table 6: Estimating path (a)

\begin{tabular}{lllll}
\hline Latent variables & $\begin{array}{l}\text { beta }- \\
\text { estimates }\end{array}$ & $\begin{array}{l}\text { P- } \\
\text { values }\end{array}$ & $\begin{array}{l}\text { Standard } \\
\text { errors }\end{array}$ & $\begin{array}{l}\text { Significance of } \\
\text { path } \\
\text { P }<0.05\end{array}$ \\
\hline I.T knowledge $\longrightarrow$ Top management support & 0.193 & 0.019 & 0.092 & Significant \\
Security concerns $\longrightarrow$ Top management support & -0.163 & 0.041 & 0.093 & Significant \\
Cost $\longrightarrow$ Top management support & -0.076 & 0.213 & 0.095 & Insignificant \\
Coercive pressure $\longrightarrow$ Top management support & -0.104 & 0.138 & 0.095 & Insignificant \\
Normative Pressure $\longrightarrow$ Top management support & 0.300 & $<0.001$ & 0.090 & Significant \\
Mimetic pressure $\longrightarrow$ Top management support & 0.176 & 0.030 & 0.093 & significant \\
\hline
\end{tabular}

Research data (2018)

Step three: Determining the relationship between the mediating variable and the dependent variable while controlling for independent variables to establish path $-\mathrm{b}$. 
Step 4: Establish total mediation if the effect of independent variables on dependent variables is zero while controlling for mediating variable.

According to [28] in determining the mediating effect, there is partial mediation if there is a significant effect of independent variable on Dependent variable in the second model which includes the mediating variable. However if the relationship between Independent variable and dependent variable is not significant then there is a perfect or complete mediating effect, assuming that the criteria for the three steps have been met. The mediation analysis results show that Top management partially mediated the relationship between I.T knowledge, Security, Normative, Mimetic pressures and e-marketing adoption. This is so because controlling the mediating variable did not make the effect of I.T knowledge, Security, Normative, Mimetic pressures on adoption of E-marketing to be zero (insignificant). However there was no mediating effect of Top management on relationship between Coercive pressures and E-marketing adoption because Coercive pressure and perceived cost of implementation had an insignificant relationship with the mediating variable (Top management) in path - a.Table 7 shows the mediated path analysis.

Table 7: Estimating significance of Mediation effect of Top management support

\begin{tabular}{llll}
\hline Latent variables & $\begin{array}{l}\text { Path-c model 1-( } \\
\beta \text {-estimates }\end{array}$ & $\begin{array}{l}\text { Path-c model 2- } \\
(\beta \text {-estimates })\end{array}$ & $\begin{array}{l}\text { Type of mediation } \\
\text { effect }\end{array}$ \\
\hline I.T knowledge $\longrightarrow$ E-marketing adoption & $0.305^{* *}$ & $0.269^{* *}$ & $\begin{array}{l}\text { Partial mediation } \\
\text { Partial mediation }\end{array}$ \\
Security concerns $\longrightarrow$ E-marketing adoption & $-0.084^{*}$ & $-0.158 *$ & No mediation \\
Coercive pressure $\longrightarrow$ E-marketing & $-0.217^{*}$ & $-0.026^{*}$ & No mediation \\
Normative pressure $\longrightarrow$ E-marketing adoption & 0.054 & 0.106 & $0.354^{* *}$ \\
Mimetic pressure $\longrightarrow$ E-marketing adoption & $0.188^{*}$ & $0.194^{*}$ & Partial mediation \\
\hline
\end{tabular}

Research data (2018)

\subsection{Variance explained- $\left(\mathbf{R}^{2}\right)$}

In correlation analysis, two values are provided in the regression output, the correlation of coefficient which is the strength and direction of the relationship between two variables "R" and Coefficient of determination- "R-squared". The square multiple correlations $\left(\mathrm{R}^{2}\right)$ is the measurement of percentage of variation in the dependent variable that is explained by a model. Correlation of Coefficient $(\mathrm{r})$ is applicable in simple linear regression having one response and one predictor variables. This is not applicable to model with multiple independent variables; the $\mathrm{R}$ squared is applicable in this case.The results for variance explained (R-squared) for all the independent variables used in the model (managers IT knowledge, Security concerns, Cost, Coercive pressures, Normative pressures, Mimetic pressures and Top management support towards adoption of E-marketing was $\mathrm{R}^{2}=0.34$ for Top management and $\mathrm{R}^{2}=0.37$ adoption of E-marketing. The explanatory power of the structural model was evaluated by examining the squared multiple correlation $\left(\mathrm{R}^{2}\right)$ value in the final dependent constructs. The primary evaluation criteria for the structural model are the $\mathrm{R}^{2}$ measures and the level of significance of the path coefficients [29]. This means that the independent variables explained $37 \%$ of the variance for adoption of E-marketing and $34 \%$ of the variance explained for top management support towards adoption of E-marketing. According to [29], interpreting acceptable level of $\mathrm{R}^{2}$ depends on the context of the study. [30] rule of thumb suggests that $R^{2}$ values above 0.67 should be substantial; above 0.33 (moderate) while above 0.19 (weak). From the above argument therefore the $\mathrm{R}^{2}$ of $37 \%$ of the variance for adoption of E-marketing and 34\% of the variance explained for Top management support towards adoption of Emarketing was considered Moderate. In addition to the coefficient of determination $\left(R^{2}\right)$ [31] recommend the computation of the Stone-Geisser's $\mathrm{Q}^{2}$ value [32]; [33] for measuring the model's predictive relevance. $\mathrm{Q}^{2}>0$ is indicative of predictive relevance; $\mathrm{q}^{2}$ values of $0.02,0.15$, and 0.35 are interpreted as weak, moderate, strong degree of predictive relevance [29]. "A $\mathrm{Q}^{2}$ with a zero or negative value indicates the model is irrelevant to prediction of the given endogenous factor" [24].Table 9 shows the results of the Stone-Geisser's $\mathrm{Q}^{2}$ coefficients results

Table 9: The Stone-Geisser's $Q^{2}$ coefficients results

\begin{tabular}{cc}
\hline Latent variables & $\mathrm{Q}^{2}$ \\
\hline E-marketing adoption & 0.475 \\
Top management support & 0.385 \\
\hline
\end{tabular}

Research data (2018) 
Vol. 8, Issue 5, May 2019

According to the analysis results the developed model had a $\mathrm{q}^{2}$ of 0.385 for Management support and $\mathrm{q}^{2}$ coefficient of 0.475 for E-marketing adoption. These results mean that the developed model has a strong degree of predictive relevance.

\subsection{Results for validation of model fitness}

The developed model showed a relatively good fit with the data collected. From the analysis, the model fit and quality indices confirmed this model to be fit with the data collected as the APC for the model was APC $=0.202$.APC values are deemed acceptable if the value is equal to or less than five. The minimum threshold requirement is that $\mathrm{P}$-values should be less than 0.05 . Table 10 Show these findings.

Table 10: Model fit and quality indices

\begin{tabular}{|c|c|c|c|c|}
\hline Quality index & Coefficient & P-value & Acceptable threshold & Comments \\
\hline Average path coefficient (APC) & 0.202 & 0.008 & $\mathrm{P}$ values to be less than 0.05 & P-value accepted \\
\hline Average R-squared (ARS) & 0.352 & $\mathrm{P}<0.001$ & $\mathrm{P}$ values to be less than 0.05 & $\begin{array}{l}\mathrm{P} \\
\text { accepted }\end{array}$ \\
\hline adjusted R-squared & 0.310 & $\mathrm{P}<0.001$ & $P$ values to be less than 0.05 & $\begin{array}{l}\mathrm{P} \\
\text { accepted }\end{array}$ \\
\hline Average block VIF (AVIF) & 1.258 & & $\begin{array}{l}\text { acceptable if }<=5 \text {, ideally }<= \\
3.3\end{array}$ & Accepted \\
\hline $\begin{array}{l}\text { Average full collinearity } \quad \text { VIF } \\
\text { (AFVIF) }\end{array}$ & 1.361 & & $\begin{array}{l}\text { acceptable if }<=5 \text {, ideally }<= \\
3.3\end{array}$ & Accepted \\
\hline
\end{tabular}

Research data (2018)

These results indicated good quality index for the model. The Average R-squared (ARS) Coefficient was ARS $=0.352$ with $\mathrm{P}$ values below 0.05 . The minimum threshold requirement is that $\mathrm{p}$-values should be less than 0.05 for the Average R-squared (ARS) of the model. This indicated good quality index for the model. The Average block VIF (AVIF) for the models was AVIF $=1.258$ which is an acceptable since the value is less than 5. This confirmed the model to be fit with the data collected. The result of the Average full collinearity (AFVIF) for the model was AFVIF= 1.361 .This also indicated good model fit with the data collected since the AFVIF value was less than five. Overally the model fit was confirmed by the quality fit indices.

\subsection{The developed Integrated Model for E-marketing adoption}

The Integrated Model for E-marketing adoption is composed of five independent latent variables, namely: Manager's I.T knowledge, Security concerns, Perceived costs of e-marketing, Coercive, Mimetic and Normative pressures. This independent variables in the model either influence Top management support or adoption of E-marketing. In this model, Top management support is the mediating variable. Figure 1 is an illustration of the developed Model

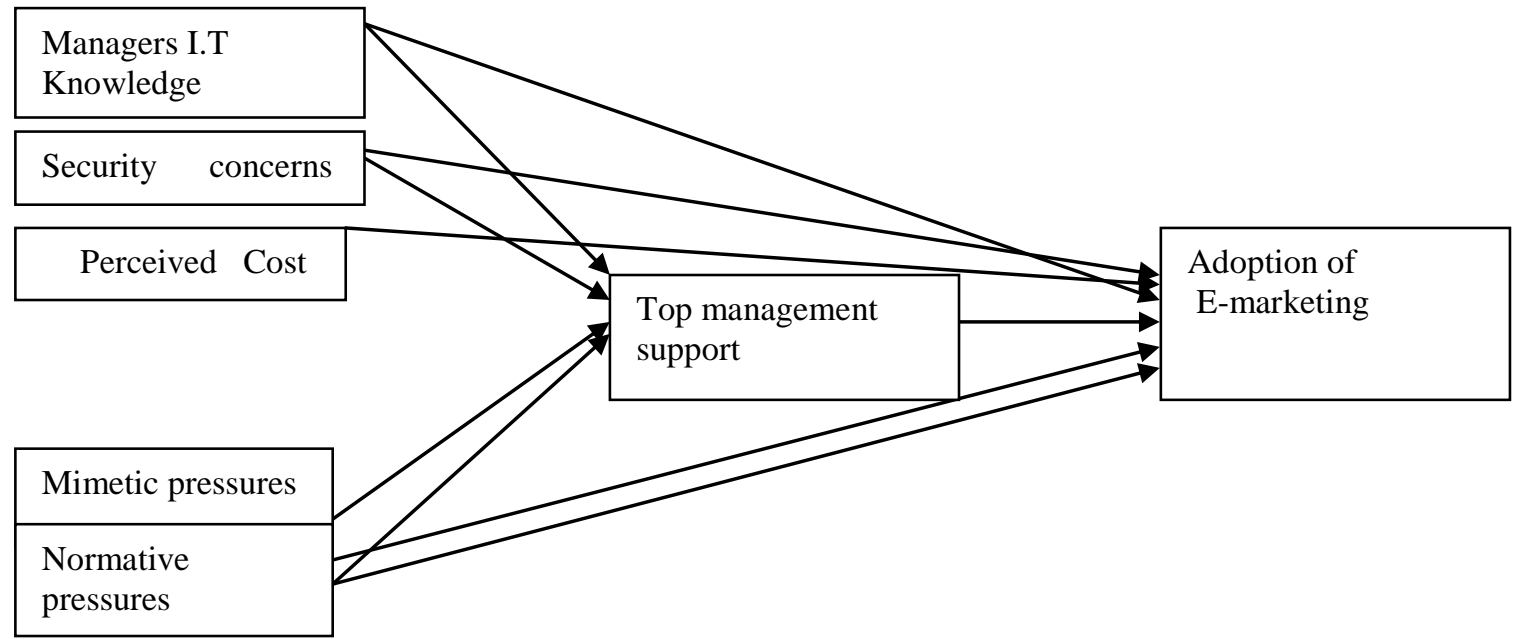

Fig.1 The Integrated Model for E-marketing adoption for small businesses 


\section{CONCLUSION}

This study has developed a model that can be used to study adoption of e-marketing in particular and Information systems innovations in general by small businesses. The developed model is based on literature from Institutional theory [15] ; [10] and Technology Organization and Environment framework (TOE) [11] in developing an Integrated Model that explains and validates the relationship between Decision makers characteristics, Technological characteristics, Institutional isomorphic pressures and adoption of E-marketing. The justification for this integration is that Manager's I.T knowledge, security concerns, Cost of implementing innovation and Top management support play a significant role in adoption of innovation. This view is supported by several studies on Information Systems adoption [2]; [34]

\section{REFFRENCES}

[1]. Verheyden, M., \& Goeman.(2013).Does (Company) Size Matter? Differences in Social Media Usage for Business Purposes; Journal of applied Science, 8(4), 1-15

[2]. Dlodlo, N \& Dhurup (2013) SMEs' adoption of enterprise applications A technology-organization-environment model Mediterranean. Journal of Social Sciences 4 (14)

[3]. U.S. Census Bureau (2014) Facts \& Data on Small Business and Entrepreneurship, found at http://sbecouncil.org/about-us/facts-and-data

[4]. MyGov.com, 2015). Jua Kali sector plays key role in economic development and job creation. Retrieved from: http://www.mygov.go.ke/smesplay-key-role-in-economic-development-and-job-creation

[5]. OECD (2017) Enterprises by business size (indicator).Retrieved on 19 March 2017 at https://data.oecd.org/entrepreneur/enterprises-bybusiness-size.htm.doi: 10.1787/31d5eeaf-en.

[6]. Nganga S. I. \& Onyango G. M. (2011).Collective Efficiency and Its Effects on Infrastructure Planning and Development for Small Manufacturing Enterprises in Kenya, International Journal of Business and Public Management: 168-193

[7]. Davies, F. D., Bagozzi, R. P., \& Warshaw, P. R. (1989) User acceptance of computer technology: a comparison of two theoretical models. Management Science Journal, 35(8), 982-1003

[8]. Venkatesh, V., Morris, M. G., Davis, G. B., \& Davis, F. D. (2003) User acceptance of information technology: Toward a unified view. MIS Quarterly, 27(3), 425-278

[9]. Ajzen, I. (1991).The theory of planned behavior. Organizational Behavior \& Human Decision Processes, 50(2), 179-211

[10]. Rogers, E. M. (1995). Diffusion of innovations (4th ed). New York: Free Press Publishers

[11]. Tornatzky, L. \& Fleischer, M.(1990). The process of technology innovation; Lexington, MA, Lexington Books

[12]. Thong, J.Y.L. (1999). An integrated model of information systems adoption in small businesses; Journal of Management Information Systems, $15(4), 187-214$

[13]. Kung, L., Cegielski. G., \& Kung, H. (2015).An integrated environmental perspective on software as a service adoption in manufacturing and retail firms: Journal of Information Technology. http://doi.org/10.1057/jit.2015.14

[14]. Oliveira, T. \& Martins, M.F. (2011) Literature Review of Information Technology Adoption Models at Firm Level Electronic .Journal Information Systems Evaluation 14 (1), 111-119

[15]. DiMaggio, P.J. \& Powell, W.W. (1983) The iron cage revisited - institutional isomorphism and collective rationality in organizational fields, American Sociological Review,48(2), 147-160.

[16]. Teo, H.H., Wei, K.K.\& Benbasat, I.(2003) Predicting intention to adopt Inter-org linkages: An institutional perspective, "MIS Quarterly",27, (1), 19-49.

[17]. Pietilä, M. (2014).The many faces of research profiling: academic leaders' conceptions of research steering. Higher Education, 67(3), 303-316. doi: $10.1007 / \mathrm{s} 10734-013-9653-5$

[18]. Lepori, B., Usher, J., \& Montauti, M. (2013). Budgetary allocation and organizational characteristics of higher education institutions: a review of existing studies and a framework for future research. Higher Education, 65(1)

[19]. Cai, Y, Mehari, Y(2015), The Use of Institutional Theory in Higher Education Research; Theory \& Method in Higher Education,1-25

[20]. Iacovou, C.L., Benbasat, I. \& Dexter, A.S. (1995), Electronic data interchange and small organizations: adoption and impact of technology, MIS Quarterly, 19 (4), 465-85

[21]. Rahman, MD. (2016). The Advantages and Disadvantages of Using Qualitative and Quantitative Approaches and Methods in Language Testing and Assessment Research: A Literature Review; Journal of Education and Learning. 6,102.

[22]. Hair, J.F.J, Anderson, R.E, Tatham, R.L, Black, W.C(1998). Multivariate Data Analysis, 5thedn, Prentice Hall, Upper Saddle River, New Jersey.

[23]. Hair, J.F., Sarstedt, M, Ringle, C.M., \& Mena, J.A.(2011) An assessment of the use of partial least squares structural equation modeling in marketing research. Journal of the Academy of Marketing Science, 40,414-433 DOI 10.1007/s11747-011-0261-6

[24]. Garson, G. D. (2016). Partial Least Squares: Regression \& Structural Equation Models Asheboro: Statistical Associates Publishing

[25]. Kline, R.B., 1998. Principles and Practice of Structural Equation Modeling. Guilford, New York, NY

[26]. Henseler, J., Ringle, C. M.,\& Sarstedt, M. (2012).Using Partial Least Squares Path Modeling in International Advertising Research: Basic Concepts and Recent Issues. Handbook of Research in International Advertising, S. Okazaki (ed.), Edward Elgar Publishing: Cheltenham

[27]. Henseler, J., Hubona \& Ray (2016), Using PLS path modeling in new technology research: updated guidelines, Industrial Management \& Data Systems, $116(1) 2-20$.

[28]. Henseler, J., Hubona \& Ray (2016), Using PLS path modeling in new technology research: updated guidelines, Industrial Management \& Data Systems, 116 (1) $2-20$.

[29]. Hair, J.F \& Ringle, C.M. \& Sarstedt, M. (2013). Partial Least Squares Structural Equation Modeling: Rigorous Applications, Better Results and Higher Acceptance. Long Range Planning, 46. 1-12

[30]. Höck, M. \& Ringle, C.M. (2006). Strategic networks in the software industry: An empirical analysis of the value continuum. IFSAM $8^{\text {th }}$ World Congress, Berlin 2006. Retrieved 1/11/2015 from http://www.iblunihh.de/IFSAM06.pdf

[31]. Hair, J.F, Hult, G.T.M, Ringle, C.M. \& Sarstedt, M. (2014). A Primer on Partial Least Squares Structural Equation Modeling, Sage, Thousand Oaks, CA.

[32]. Geisser, S. (1974). A predictive approach to the random effects model. Biometrika, 61(1), 101-107.

[33]. Stone, M. (1974).Cross-validatory choice and assessment of statistical predictions. Journal of the Royal Statistical Society, 36(2), 111-147.

[34]. Said, M.A.A. \& Azizan, A.N (2013) Factors Affecting Ecommerce Adoption among Hotel Industry in Libya. Proceeding of the International Conference on Social Science Research. 4-5 June 2013, Penang, Malaysia 